\title{
Comparison of survival in elderly patients treated with uretero-cutaneostomy or ileal conduit after radical cystectomy
}

\author{
Shang Huang ${ }^{\dagger}$, Hanzhong Chen ${ }^{\dagger}$, Teng Li, Xiaoyong Pu, Jiumin Liu and Xuecheng Bi ${ }^{*}$ (D)
}

\begin{abstract}
Background: In bladder cancer patients with age $\geq 80$ years old, there have been controversies in performing uretero-cutaneostomy or ileal conduit as urinary diversion after radical cystectomy. Limited study evaluated overall survival (OS) and cancer-specific survival (CSS) between the two urinary diversions in elderly patients. This study is to compare OS and CSS between uretero-cutaneostomy and ileal conduit after radical cystectomy in bladder cancer patients with age $\geq 80$ years old.
\end{abstract}

Patients and methods: Data were extracted from the Surveillance, Epidemiology, and End Results (SEER) database. Bladder cancer patients diagnosed between 2004 and 2016 with age $\geq 80$ years old who underwent radical cystectomy with either UC or IC were selected. After propensity score matching, Cox regression and Kaplan-Meier analysis were used to analyze the survival. We calculated statistical power for survival.

Results: Of 1394 patients who met the inclusion criteria, 1093 underwent ileal conduit and 301 underwent ureterocutaneostomy. After propensity score matching, 285 patients were included in each group. Multivariable Cox analysis showed urinary diversion was not a risk factor of OS and CSS (HR 1.044, [95\% Cl 0.867-1.257] and 1.012 [0.748-1.368], respectively). Both OS and CSS were not significantly different, with median survival of ileal conduit and uretero-cutaneostomy were 19 [16-24] months and 19 [15-26] months respectively. Additionally, We found OS had the following risk factors: tumor stage (distant vs regional vs localized, 5.332 [3.610-7.875] vs 1.730 [1.375$2.176]$ vs 1), node density (>0.2 vs $\leq 0.2$ vs none, 1.410 [1.047-1.898] vs 0.941 [0.658-1.344] vs 1$)$ and age (1.067 [1.032-1.103] for each year). While CSS had the following risk factors: tumor stage (distant vs regional vs localized, 4.035 [2.046-7.959] vs 2.476 [1.651-3.713] vs 1), node density (>0.2 vs $\leq 0.2$ vs none, 2.501 [1.645-3.804] vs 1.062 [0.590-1.914] vs 1) and tumor size (greater than $3 \mathrm{~cm}$ vs less than $3 \mathrm{~cm}, 1.596$ [1.057-2.412] vs 1). Our analysis obtained 0.707 power for overall survival.

Conclusion: Urinary diversion by uretero-cutaneostomy or by ileal conduit was not associated with overall and cancer-specific survival. It is reasonable to consider uretero-cutaneostomy as a regular procedure of urinary diversion in elderly bladder cancer patients after radical cystectomy to avoid associate complications.

Keywords: Urinary bladder neoplasms, Urinary diversion, Aged, 80 and over, SEER program

\footnotetext{
* Correspondence: doctorbi1975@163.com

† Shang Huang and Hanzhong Chen contributed equally to this work.

Department of Urology, Guangdong Provincial People's Hospital, Guangdong Academy of Medical Sciences, No.106, Zhongshan 2nd Road, Yuexiu District, Guangzhou, Guangdong, China
}

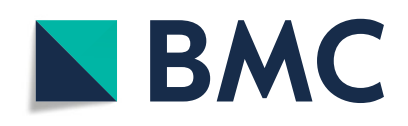

(c) The Author(s). 2021 Open Access This article is licensed under a Creative Commons Attribution 4.0 International License, which permits use, sharing, adaptation, distribution and reproduction in any medium or format, as long as you give appropriate credit to the original author(s) and the source, provide a link to the Creative Commons licence, and indicate if changes were made. The images or other third party material in this article are included in the article's Creative Commons licence, unless indicated otherwise in a credit line to the material. If material is not included in the article's Creative Commons licence and your intended use is not permitted by statutory regulation or exceeds the permitted use, you will need to obtain permission directly from the copyright holder. To view a copy of this licence, visit http://creativecommons.org/licenses/by/4.0/ The Creative Commons Public Domain Dedication waiver (http://creativecommons.org/publicdomain/zero/1.0/) applies to the data made available in this article, unless otherwise stated in a credit line to the data. 


\section{Introduction}

Radical cystectomy is one of the most effective treatments to improve survival in bladder cancer patients [1], and consequently becomes first-line procedure of muscle-invasive bladder cancer. Although orthotopic neobladder provides better function than ileal conduit (IC) or uretero-cutaneostomy (UC), more complications occur [2]. Given that continence is inferior in elderly patients who underwent orthotopic neobladder [3] and UC has similar health-related quality of life (HRQoL) due to lower complication rate and to lower expectations [4], UC and IC are more commonly used than continent urinary diversion in elderly patients after removal of urinary bladder [5].

UC is the simplest form of urinary diversion which directly anastomose bilateral ureters to the skin. While IC is more complicated since gastrointestinal segments are detached from digestive tract to form the conduit, and the partitioned digestive tract are reconnected. Due to the smaller diameter of ureters, stricture at skin level is more frequent in UC [6]. Thus, many centers choose IC as standard procedure of urinary diversion in patients who are not suitable for orthotopic neobladder.

However, elderly patients present more comorbidities and shorter life expectancy. Significantly lower survivorship for elderly is observed. Each age increasing leads to $0.2 \%$ higher risk of death [7]. Comorbidity in elderly patients is a predictor of cancer-independent mortality [8], leading to shortened overall survival (HR 1.26, $p=0.016$ ) [9]. Furthermore, compared with IC, operating time is significantly shorter for UC [10]. Longer operating time is an independent risk factor of Clavien III-V complications (OR 1.005, 95\% CI 1.002-1.007 per minute) [11], and Clavien III-V complications is an independent predictor of high cost (OR 12.7, 95\% CI 9.63-16.8, [12]). Besides operating time, UC has a shorter stay in intensive care unit ( 0.9 vs. 2.2 days, $p<0.001$ ), and lower Clavien III-V complications $(2.1 \%$ vs. $14.2 \%, p=0.01)$ compared with IC in patients with age $\geq 75$ years old [11, 13], and will not significantly impact quality of life of elderly patients [10]. Consequently, UC is more likely to be performed in high-risk elderly patients [3].

Most studies comparing UC and IC focused on complications and early mortality. Given that UC incurs less perioperative and postoperative complications than IC but more late complications such as ureteral obstruction at skin level, balance of benefits, risks and life expectancy should be emphasized in elderly patients. Based on evidences mentioned above, we hypothesize UC would have similar overall survival and cancer- specific survival compared with IC. This research is the first time to evaluate longterm survival of UC and IC in patients with age $\geq 80$ years old and will provide further information on urinary diversion selection.

\section{Methods}

\section{Study population and grouping}

Data were extracted from the Surveillance, Epidemiology, and End Results (SEER) database [14]. Data extraction and analysis were completed from November, 2019 to Februrary, 2020. The inclusion criteria are listed below:

1) Age at diagnosis $\geq 80$ years old.

2) Diagnosed between 2004 and 2016.

3) Had microscopically diagnosed bladder cancer.

4) Underwent radical cystectomy with either UC or IC.

We included all histologic types of bladder cancer. Sociodemographic and clinical characteristics were selected as baseline data. In detail, we selected age, sex, marital status, year of diagnosis, race/ethnicity, insurance, tumor grade, tumor stage, tumor size, and node density. Marital status was categorized as 'Married', 'Single', and 'Unknown'. We combined all living-alone status into 'Single'. Tumor grade was categorized as 'Urothelial Carcinoma, Low Grade', 'Urothelial Carcinoma, High Grade', 'Urothelial Carcinoma, NOS' (NOS indicated not otherwise specified), and 'non-Urothelial Carcinoma'. We used 'SEER Summary Stage 2000' as a comprehensive interpretation to TNM stage system. In detail, tumor stage was categorized as 'Localized' which means Tis T2bNOM0, 'Regional' which means T3a T4N0M0 or TanyN1 N2M0, 'Distant' which means TanyN3M0 or TanyNanyM1, and 'Unknown'. Tumor size was categorized as 'Less than $3 \mathrm{~cm}$ ', 'Greater than $3 \mathrm{~cm}$ ', and 'Unknown'. Node density was calculated as nodes positive divided by nodes examined after surgery. If no node was positive, node density was categorized as 'None'. If any nodes were positive, node density was categorized as ' $\leq 0.2$ ' and ' $>0.2$ '. If unknown nodes were positive, node density was categorized as 'Unknown'.

\section{Statistical analysis}

Patients were divided into IC or UC group according to urinary diversion they had received. We used propensity score matching with 1:1 ratio by baseline characteristics stated above as pseudo randomization. All statistical analysis used data after matching. We performed power analysis for survival to calculate 
the statistical power of this study according to Freedman et al. [15]. Little information was provided for postulated hazard ratio from previous studies, so we set postulated hazard ratio in a post hoc manner.

Risk factors were determined using Cox proportional hazardous regression model. The primary outcome is overall survival (OS). The secondary outcome is cancer-specific survival (CSS). OS and CSS were evaluated by Kaplan-Meier method with Log-rank test. The Analysis of Variance or Kruskal-Wallis test was used to analyze continuous variables. Chi-square test or Fisher's exact test was used to analyze categorical variables. All statistical tests were 2 -sided. $p$-value $<0.05$ was considered statistically significant. $\mathrm{R}$ software version 3.6.3 with packages survival, survminer, MatchIt, and powerSurvEpi was used to perform calculation and graphing.

\section{Results}

Clinical and sociodemographic characteristics

Of 1394 patients who met the inclusion criteria, median age was 82.0 (interquartile range 81.0-85.0), with $1206(86.5 \%)$ were men and 188 (13.5\%) were women. Before matching, 1093 patients were included in IC group and 301 patients were included in UC group. IC group had fewer male patients (83.8\% vs $96.3 \%, p<0.001)$, later year of diagnosis (between 2004 and $2010,60.2 \%$ vs $76.7 \%, p<0.001$ ), more insured patients $(76.0 \%$ vs $63.8 \%, p<0.001)$ and different node density $(p=0.021)$ than UC group. While age, marital status, race/ethnicity, tumor grade, tumor stage and tumor size had no significant differences between two groups. After matching, 285 patients were in each group. All sociodemographic and clinical characteristics had no significant differences. Patient demographics before and after propensity score matching are summarized in Table 1.

\section{Risk factor of OS and CSS}

Multivariable Cox proportional hazardous regression model showed that UC was associated with neither OS nor CSS (HR 1.044, 95\% CI 0.867-1.257 and HR 1.012 , 95\% CI $0.748-1.368$, respectively). But tumor stage and node density were risk factors for both OS and CSS. Compared to localized tumor, regional and distant involvement had decreased OS (HR 1.730, 95\% CI 1.375-2.176 and HR 5.332, 95\% CI 3.6107.875), as well as CSS (HR 2.476, 95\% CI 1.6513.713 and HR 4.035, 95\% CI 2.046-7.957). Compared to zero node density ('None'), > 0.2 node density had decreased OS (HR 1.41, 95\% CI 1.047-1.898), as well as CSS (HR 2.501, 95\% CI 1.645-3.804). Age increasing had negative correlation with OS (HR 1.067,
95\% CI 1.032-1.103 for each year). Tumor size greater than $3 \mathrm{~cm}$ had negative correlation with CSS (HR 1.596, 95\% CI 1.057-2.412). Test of the proportional hazard assumption based on Schoenfeld residuals showed $p>0.05$ for all covariates. Thus, all sociodemographic and clinical characteristics were taken into consideration during Cox analysis. The multivariable Cox analysis results are summarized in Table 2.

\section{Survival comparison between IC and UC}

Kaplan-Meier curve of OS showed median survival of IC and UC were 19 months (95\% CI 16-24) and 19 months (95\% CI 15-26). No significant differences are observed $(p=0.652)$. Furthermore, no significant difference was found in Kaplan-Meier curve of CSS $(p=0.936)$. The two curves are shown in Figs. 1 and 2 .

\section{Power analysis}

Given that we obtained upper CI of 1.257 in multivariable Cox analysis between IC and UC, we set postulated HR to 1.257 for power analysis. Power analysis showed that we had achieved 0.707 power for OS and 0.362 power for CSS. To reduce ambiguity of power analysis we drew a power-effect curve to clearly show relation between power and postulated HR. The power-effect curve is shown in Fig. 3.

\section{Discussion}

Natural history of bladder cancer is dreadful, with $38 \%$ patients develop metastasis after 6 months if untreated, and only 5\% patients would survive after 5 years [16, 17]. Radical cystectomy is the standard treatment for muscle invasive bladder cancer. However, it is a challenge to determine the best urinary diversion for different patient populations after radical cystectomy.

Current studies comparing UC and IC mainly focus on perioperative complications and early mortality, and the results vary [18]. In elderly patients especially those with cardiac or pulmonary comorbidities, IC or UC are recommended to reduce complications. UC has shorter operating time, shorter stay in intensive care unit, shorter fasting period, and lower Clavien III-V complications compared with IC in elderly patients $[6,10,11,13$ 19]. While some studies failed to conclude such advantages [20, 21].

For now, few studies have compared UC with IC for OS and CSS, let alone long-term survival. Big data in SEER database gives us a chance to monitor UC and IC. In this study we offered a retrospective analysis based on SEER database. In our study, we 
Table 1 Patient demographics before and after propensity score matching

\begin{tabular}{llll}
\hline & Ileal Conduit & $\begin{array}{l}\text { Uretero- } \\
\text { cutaneostomy }\end{array}$ & $\mathbf{p}$ \\
\hline Before Matching & &
\end{tabular}

Before Matching

Age (median [IQR])

$\operatorname{Sex}(n(\%))$

Female

Male

Marital Status (n (\%))

Married

Single

Unknown

Year of Diagnosis $(n(\%))$

$$
\text { 2004 } 2010
$$

$2011 \sim 2016$

Race/Ethnicity ( $(\%)$ )

White

Insurance (n(\%))

Insured

Uninsured

Unknown

Tumor Grade (n (\%))

Urothelial Carcinoma,

Low Grade

Urothelial Carcinoma,

High Grade

Urothelial Carcinoma,

NOS

non-Urothelial Carcinoma

$\begin{array}{lll}1093 & 301 & \\ 82.00 & 83.00 & 0.596 \\ {[81.00,85.00]} & {[81.00,85.00]} & \\ & & <0.001\end{array}$

Tumor Stage (n (\%))

$$
\text { Localized }
$$

Regional

Distant

Unknown

Tumor Size (n (\%))

Less than $3 \mathrm{~cm}$

Greater than $3 \mathrm{~cm}$

Unknown

Node Density (n(\%))

None

$\leq 0.2$

$>0.2$

Unknown

After Matching

Table 1 Patient demographics before and after propensity score matching (Continued)

\begin{tabular}{llll}
\hline & Ileal Conduit & $\begin{array}{l}\text { Uretero- } \\
\text { cutaneostomy }\end{array}$ & $\mathbf{p}$ \\
\hline Age (median [IQR]) & 82.00 & 83.00 & 0.689 \\
& {$[81.00,84.00]$} & {$[81.00,85.00]$} & \\
$\operatorname{Sex}(\mathrm{n}(\%))$ & & & 0.835
\end{tabular}

$177(16.2)$

$11(3.7)$

$916(83.8)$

$290(96.3)$

695 (63.6)

$187(62.1)$

361 (33.0)

$96(31.9)$

$37(3.4)$

$18(6.0)$

$658(60.2)$

231 (76.7)

$435(39.8)$

$70(23.3)$

995 (91.0)

$273(90.7)$

$48(4.4)$

$13(4.3)$

$50(4.6)$

$15(5.0)$

$831(76.0) \quad 192(63.8)$

$6(0.5)$

$1(0.3)$

$256(23.4)$

$108(35.9)$

$33(3.0) \quad 16(5.3)$

$946(86.6)$

$252(83.7)$

$15(1.4)$

$5(1.7)$

$99(9.1)$

$28(9.3)$

Female

Male

Marital Status (n (\%))

Married

Single

Unknown

Year of Diagnosis $(n(\%))$

$2004 \sim 2010$

$2011 \sim 2016$

Race/Ethnicity (n(\%))

White

0.940

Black

Asian

Insurance (n(\%))

Insured

$<0.001$

Uninsured

Unknown

Tumor Grade (n (\%))

Urothelial Carcinoma,

Low Grade

0.261

Urothelial Carcinoma,

High Grade

Urothelial Carcinoma,

NOS

non-Urothelial Carcinoma

Tumor Stage (n (\%))

Localized

0.159

$398(36.4) \quad 123(40.9)$

$620(56.7)$

$151(50.2)$

$72(6.6)$

$26(8.6)$

$3(0.3)$

$1(0.3)$

$262(24.0)$

68 (22.6)

$508(46.5)$

$127(42.2)$

$323(29.6)$

$106(35.2)$

611 (55.9)

$160(53.2)$

$133(12.2)$

$22(7.3)$

$117(10.7)$

38 (12.6)

$232(21.2)$

$81(26.9)$

Distant

Tumor Size (n (\%))

Less than $3 \mathrm{~cm}$

Greater than $3 \mathrm{~cm}$

0.169

Unknown

Node Density (n(\%))

0.021

None

$>0.2$

$13(4.6) \quad 11(3.9)$

$272(95.4) \quad 274(96.1)$

$183(64.2) \quad 180(63.2)$

$93(32.6) \quad 93(32.6)$

$9(3.2)$

$12(4.2)$

$231(81.1) \quad 215(75.4)$

$54(18.9) \quad 70(24.6)$

0.655

$258(90.5) \quad 262(91.9)$

$11(3.9) \quad 12(4.2)$

$16(5.6) \quad 11(3.9)$

0.895

$186(65.3) \quad 190(66.7)$

$1(0.4) \quad 1(0.4)$

$98(34.4) \quad 94(33.0)$

$15(5.3) \quad 13(4.6)$

$241(84.6) \quad 240(84.2)$

$5(1.8) \quad 5(1.8)$

$24(8.4) \quad 27(9.5)$

$106(37.2) \quad 116(40.7)$

$154(54.0) \quad 146(51.2)$

$24(8.4) \quad 22(7.7)$

$1(0.4)$

$1(0.4)$

$74(26.0)$

$67(23.5)$

$127(44.6)$

$123(43.2)$

84 (29.5)

$95(33.3)$

$166(58.2) \quad 155(54.4)$

$24(8.4)$

$22(7.7)$

38 (13.3)

34 (11.9)

57 (20.0)

74 (26.0)

NOS Not Otherwise Specified, IQR Interquartile Range. Node density is nodes positive divided by nodes examined after surgery

0.818

0.851

0.581

0.408

285 
Table 2 Multivariable Cox proportional hazardous regression model for overall survival and cancer-specific survival

\begin{tabular}{|c|}
\hline Characteristics \\
\hline Overall Survival \\
\hline Urinary Diversion \\
\hline Ileal Conduit \\
\hline Uretero-cutaneostomy \\
\hline Age \\
\hline Sex \\
\hline Female \\
\hline Male \\
\hline Marital Status \\
\hline Married \\
\hline Single \\
\hline Unknown \\
\hline Year of Diagnosis \\
\hline $2004 \sim 2010$ \\
\hline $2011 \sim 2016$ \\
\hline Race/Ethnicity \\
\hline White \\
\hline Black \\
\hline Asian \\
\hline Insurance \\
\hline Insured \\
\hline Uninsured \\
\hline Unknown \\
\hline Tumor Grade \\
\hline Urothelial Carcinoma, Low Grade \\
\hline Urothelial Carcinoma, High Grade \\
\hline Urothelial Carcinoma, NOS \\
\hline non-Urothelial Carcinoma \\
\hline Tumor Stage \\
\hline Localized \\
\hline Regional \\
\hline Distant \\
\hline Unknown \\
\hline Tumor Size \\
\hline Less than $3 \mathrm{~cm}$ \\
\hline Greater than $3 \mathrm{~cm}$ \\
\hline Unknown \\
\hline Node Density \\
\hline None \\
\hline$\leq 0.2$ \\
\hline$>0.2$ \\
\hline Unknown \\
\hline Cancer-Specific Survival \\
\hline Urinary Diversion \\
\hline Ileal Conduit \\
\hline
\end{tabular}

Hazard Ratio $[95 \% \mathrm{Cl}]$

p

.

1 [Reference]

1.044 [0.867-1.257]

$1.067[1.032-1.103]$

1 [Reference]

0.857 [0.521-1.411]

1 [Reference]

1.018 [0.828-1.251]

$1.039[0.593-1.822]$

1 [Reference]

$0.923[0.700-1.217]$

1 [Reference]

0.894 [0.555-1.440]

0.911 [0.574-1.445]

1 [Reference]

1.136 [0.156-8.259]

1.005 [0.814-1.241]

1 [Reference]

1.228 [0.777-1.941]

1.024 [0.461-2.276]

1.533 [0.891-2.638]

1 [Reference]

1.730 [1.375-2.176]

$5.332[3.610-7.875]$

3.017 [0.679-13.411]

1 [Reference]

1.185 [0.930-1.510]

$1.253[0.969-1.619]$

1 [Reference]

0.941 [0.658-1.344]

0.737

1.410 [1.047-1.898]

$1.487[1.167-1.895]$

0.024

0.001

0.569

0.644

0.379

0.953

$<0.001$

$<0.001$

0.170
1 [Reference]
Table 2 Multivariable Cox proportional hazardous regression model for overall survival and cancer-specific survival (Continued)

\begin{tabular}{lll}
\hline Characteristics & Hazard Ratio $[\mathbf{9 5 \%} \mathbf{C l}]$ & $\mathbf{p}$ \\
\hline Uretero-cutaneostomy & $1.012[0.748-1.368]$ & 0.940 \\
Age & $0.983[0.928-1.041]$ & 0.561 \\
Sex & & \\
$\quad$ Female & 1 Reference] & \\
$\quad$ Male & $0.795[0.374-1.690]$ & 0.551 \\
Marital Status & & \\
$\quad$ Married & $1[$ Reference] & \\
Single & $1.297[0.934-1.801]$ & 0.120 \\
$\quad$ Unknown & $1.308[0.558-3.065]$ & 0.537 \\
Year of Diagnosis & & \\
2004 2010 & $1[$ Reference] & \\
2011 2016 & $1.242[0.828-1.863]$ & 0.294
\end{tabular}

Race/Ethnicity

White

Black

1 [Reference]

$0.768[0.336-1.756] \quad 0.532$

Asian

$0.795[0.367-1.724]$

0.56

Insurance

Insured

Uninsured

Unknown

Tumor Grade

Urothelial Carcinoma, Low Grade

Urothelial Carcinoma, High Grade

Urothelial Carcinoma, NOS

non-Urothelial Carcinoma

1 [Reference]

$2.707[0.354-20.679] \quad 0.337$

$1.118[0.789-1.583] \quad 0.532$

Tumor Stage

Localized

Regional

Distant

Unknown

Tumor Size

Less than $3 \mathrm{~cm}$

Greater than $3 \mathrm{~cm}$

1 [Reference]

$0.934[0.482-1.807] \quad 0.838$

$0.688[0.185-2.556] \quad 0.577$

$1.241[0.547-2.813] \quad 0.606$

1 [Reference]

$2.476[1.651-3.713] \quad<0.001$

$4.035[2.046-7.959] \quad<0.001$

$3.093[0.354-27.006] \quad 0.307$

1 [Reference]

$1.596[1.057-2.412] \quad 0.026$

Unknown

$1.378[0.872-2.176]$

0.17

Node Density

None

1 [Reference]

$\leq 0.2$

$1.062[0.590-1.914]$

0.840

$>0.2$

2.501 [1.645-3.804]

$<0.001$

Unknown

1.995 [1.340-2.969]

0.001

NOS Not Otherwise Specified, Cl Confidence Interval. Node density is nodes positive divided by nodes examined after surgery 


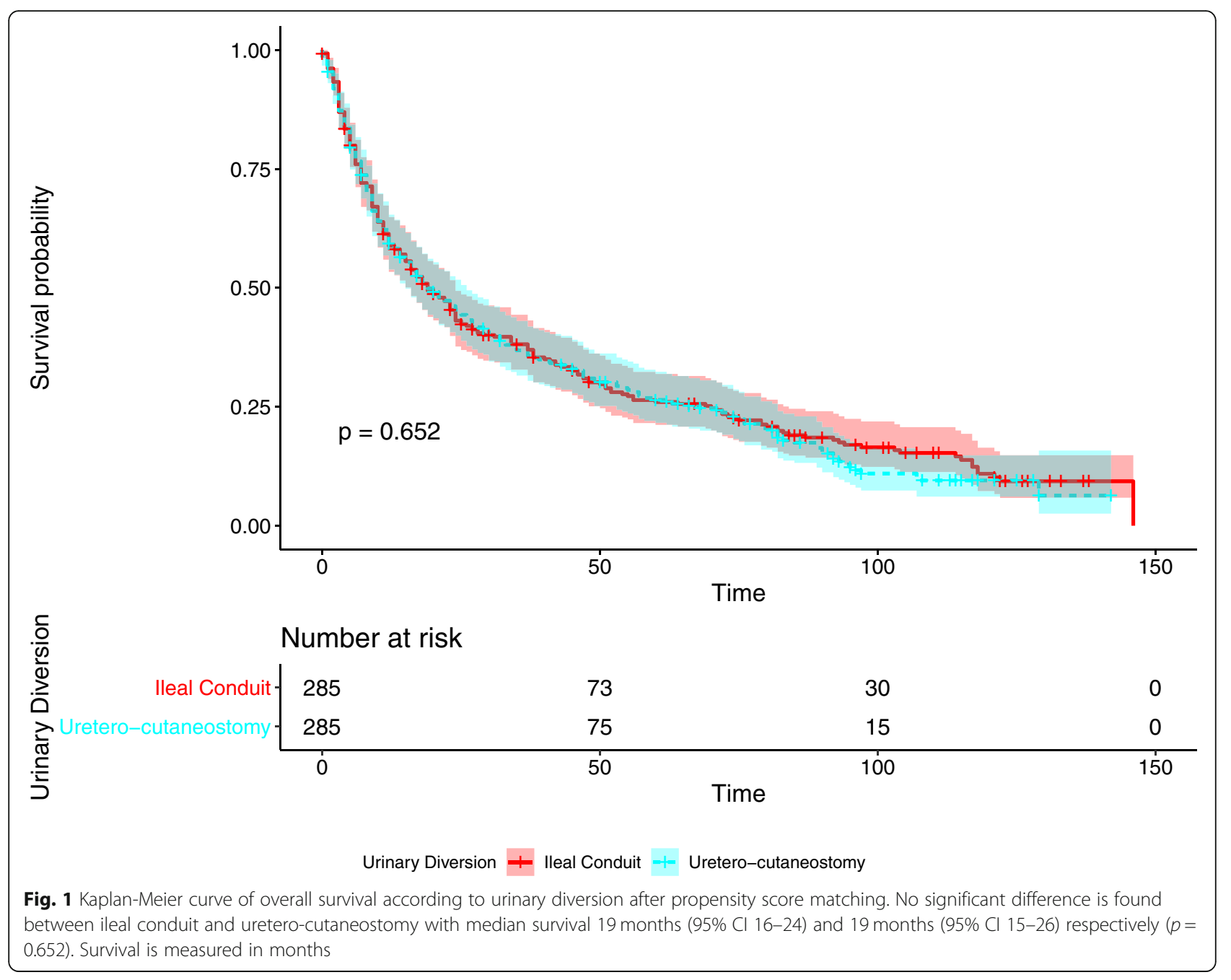

used propensity score matching by 10 socioeconomic and clinical characteristics to minimize potential bias. During the matching process, we found newly diagnosed patients who were diagnosed between $2011 \sim 2016$ were more likely to undergo IC. This is reasonable because wide spread of laparoscopic and robotic surgery could ease concerns about perioperative complications. However, this shift of surgical technique has not brought us survival benefit yet. According to our analysis. The $95 \%$ CI was $0.828-$ 1.863 .

After propensity score matching, our results showed IC and UC have similar OS and CSS. In study by Garde et al. [22], UC is not a risk factor compared with IC for OS (HR 1.86, 95\% CI 0.695.03), but lymph node involvement is (HR 8.56, 95\% CI 1.57-46.73). This is consistent with our findings that UC is not a risk factor but tumor stage is. Moreover, we found node density $>0.2$ could significantly impact OS and CSS, indicating node density could potentially become a predictor of survival in clinical setting. To summarize, it is patients' somatic function and clinical characteristics but not urinary diversion which determine OS and CSS. Thus, UC could be a regular urinary diversion technique for patients with age $\geq 80$ years old.

The main drawback of UC is stricture at skin level. If left ureter has to be connected to right ureter first other than pulled out of right abdominal skin directly, the ureter-ureter anastomosis could also be an obstructive site. Clean intermittent dilation with a disinfectant stick by patient himself could be a solution to skin-level obstruction. Ureter-ureter anastomosis stricture may require long-term ureter stent. Few complications are observed with replacement every 6 months [23]. However, our experience shows that under most circumstances the left ureter is long enough to be 


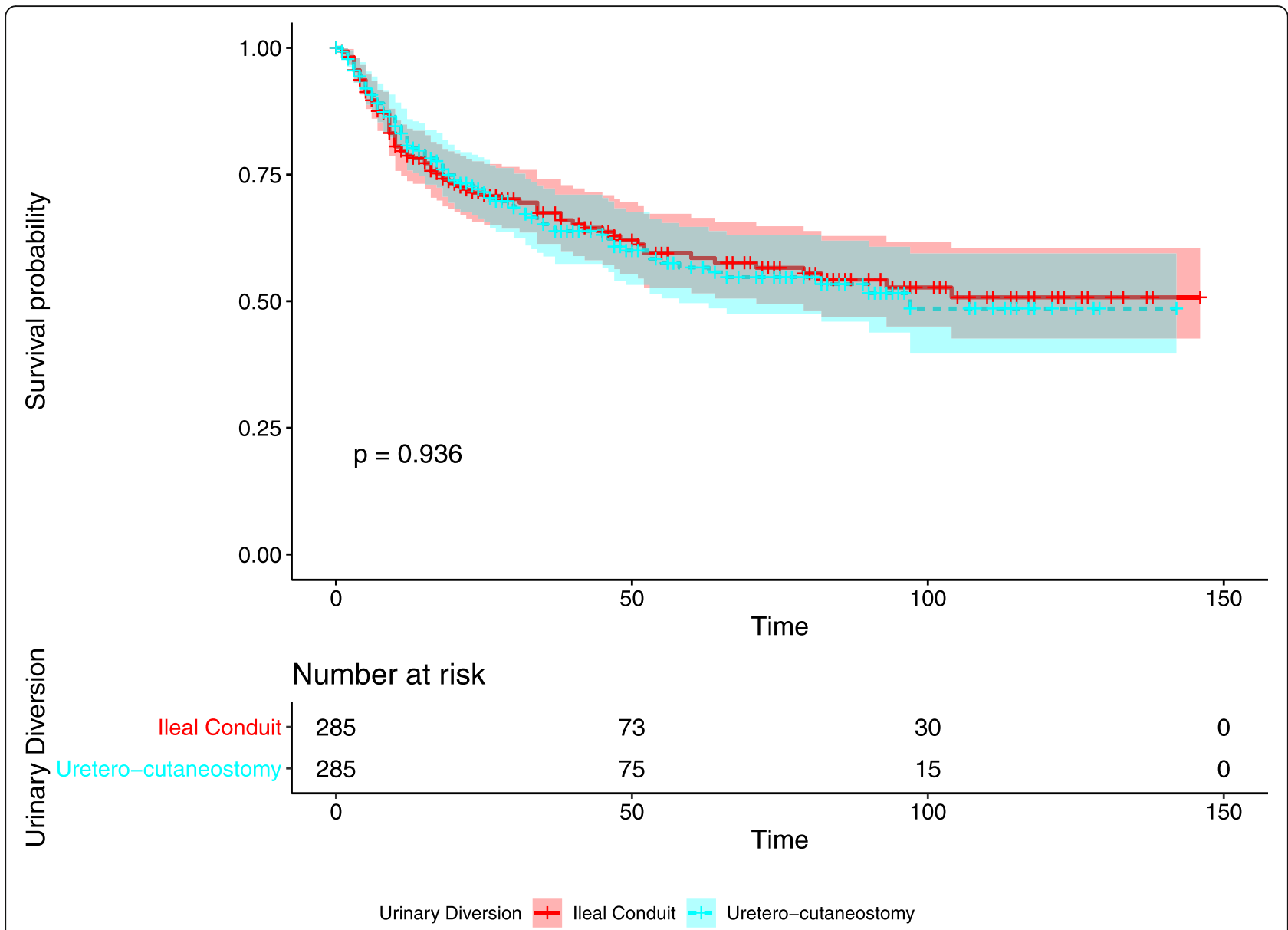

Fig. 2 Kaplan-Meier curve of cancer-specific survival according to urinary diversion after propensity score matching. No significant difference is found between ileal conduit and uretero-cutaneostomy $(p=0.936)$. Survival is measured in months

fixed at right abdominal skin directly, even in an extraperitoneal way.

Few studies compared survival of IC and UC, therefore little information could be provided on postulated HR. We set postulated HR to 1.257 in power calculation in a post hoc manner because in multivariable Cox analysis the upper CI of UC compared with IC was 1.257. Hence, we gained 0.707 power for OS. We have further calculated that to achieve 0.8 power with 1.1 postulated HR and 0.05 alpha, approximately 2700 patients should be included in each group. The actual number depends on proportion of censored data. To reduce ambiguity of power analysis we drew a power-effect curve to clearly show relation between power and postulated HR. This will help further interpretation of this study.

There are limitations in our study.

Firstly, this study is retrospective with inevitable selection bias. Although we attempt to balance two groups by propensity score matching, some important sociodemographic and clinical characteristics are missing due to lack of data in SEER database. Former studies suggested comorbidity has negative impact on survival $[9,24]$. Charlson Comorbidity Index (CCI) may be a better survival predictor than age alone $[25,26]$. Such sociodemographic and clinical characteristics should be taken into consideration in future studies.

Secondly, we did not take functional outcomes into analysis. The reason is similar that such outcomes are not recorded in SEER database. Early research showed similar glomerular infiltration rate between IC and continent pouch [27], while UC results in slight loss of renal function at approximately $8 \mathrm{ml} / \mathrm{min} / 1.73 \mathrm{~m}^{2}$ [19]. Although renal function deterioration is mainly observed in preoperative renal disease patients [28] and may not be a lethal cause in clinical setting, functional outcomes should be evaluated in large cohort in future studies. 

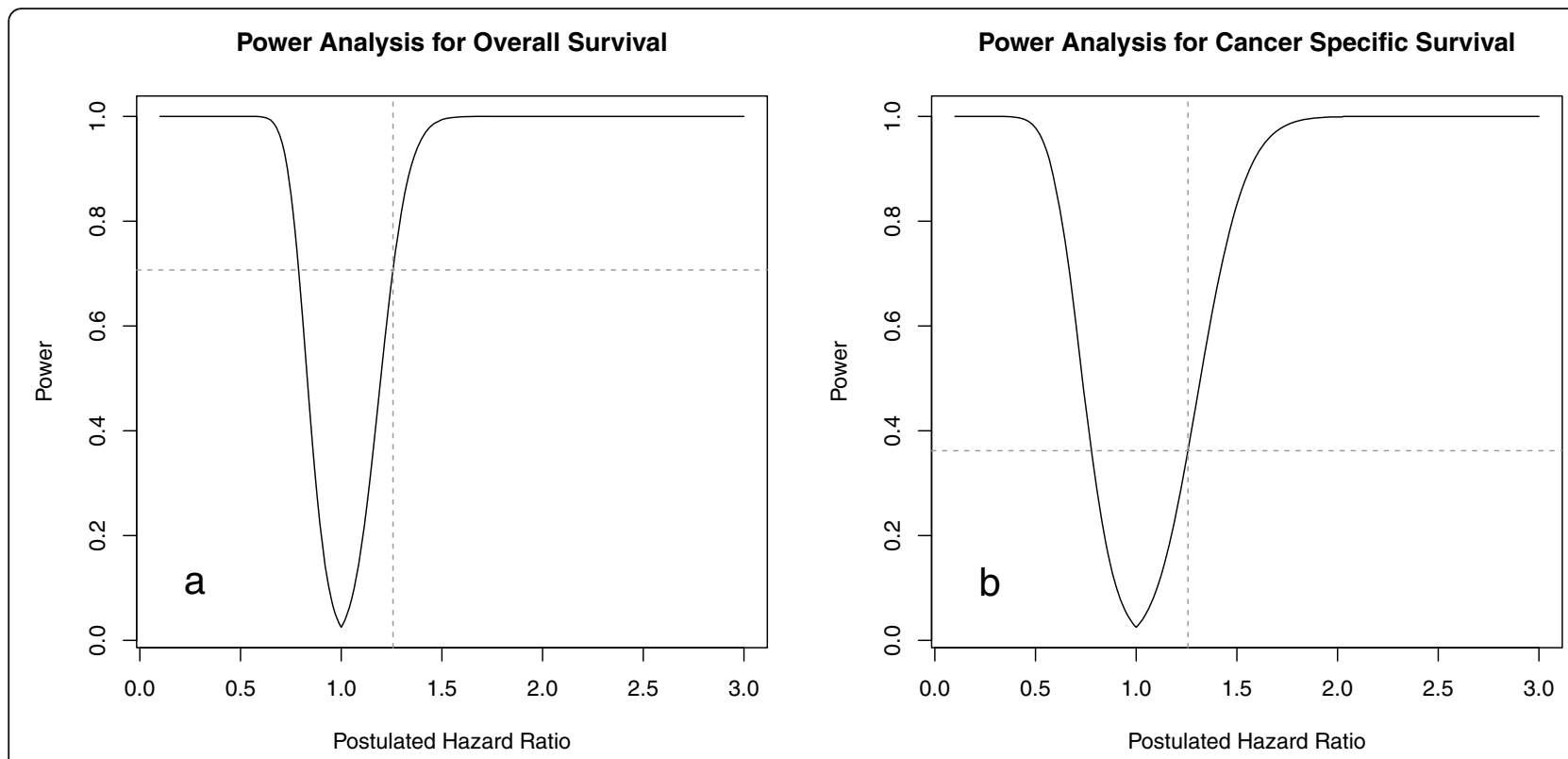

Fig. 3 Power-effect curve of overall survival (a) and cancer-specific survival (b) with $N=570$ and alpha $=0.05$. Vertical dotted line indicates postulated hazard ratio of 1.257; Horizontal dotted line indicates the power; $N=570$ because 285 patients are in each urinary diversion group

\section{Conclusion}

Uretero-cutaneostomy provides similar overall survival and cancer-specific survival compared with ileal conduit. Considering a lower perioperative and postoperative complication rate than ileal conduit, uretero-cutaneostomy could become a regular urinary diversion technique for patients with age $\geq 80$ years old.

\section{Acknowledgements}

This study is supported by Guangdong Medical Research Foundation, No.B2018208.

\section{Authors' contributions}

SH: Project development, Data collection, Data analysis, Manuscript writing. HC: Project development, Data collection, Data analysis, Manuscript writing. TL: Project development, Data collection, Data analysis. XP: Project development, Manuscript editing. JL: Project management, Manuscript editing. XB: Project management, Data analysis, Manuscript editing. All authors read and approved the final manuscript.

\section{Funding}

This study is supported by Guangdong Medical Research Foundation, No.B2018208. The fund was used for literature acquisition.

\section{Availability of data and materials}

The dataset supporting the conclusions of this article is available in the Surveillance, Epidemiology, and End Results (SEER) database. The URL of the database is https://seer.cancer.gov/data.

\section{Ethics approval and consent to participate}

Data extraction and usage has been approved by SEER Program.

\section{Consent for publication}

Not applicable.

\section{Competing interests}

Shang Huang and Xuecheng Bi report grant from Health Commission of Guangdong Province, during the conduct of the study.
Received: 15 June 2020 Accepted: 31 October 2020

Published online: 13 January 2021

\section{References}

1. Weiner AB, Keeter MK, Manjunath A, Meeks JJ. Discrepancies in staging, treatment, and delays to treatment may explain disparities in bladder cancer outcomes: An update from the National Cancer Data Base (20042013). Urol Oncol. 2018;36(237):e239-7 e217.

2. Nieuwenhuijzen JA, de Vries RR, Bex A, van der Poel HG, Meinhardt W, Antonini N, Horenblas S. Urinary diversions after cystectomy: the association of clinical factors, complications and functional results of four different diversions. Eur Urol. 2008:53:834-42 discussion 842-834.

3. Hautmann RE, Abol-Enein H, Davidsson T, Gudjonsson S, Hautmann SH, Holm HV, Lee CT, Liedberg F, Madersbacher S, Manoharan M, et al. ICUDEAU International Consultation on Bladder Cancer 2012: Urinary diversion. Eur Urol. 2013;63:67-80.

4. Vakalopoulos I, Dimitriadis G, Anastasiadis A, Gkotsos G, Radopoulos D. Does intubated uretero-ureterocutaneostomy provide better health-related quality of life than orthotopic neobladder in patients after radical cystectomy for invasive bladder cancer? Int Urol Nephrol. 2011:43:743-8.

5. Nahar B, Koru-Sengul T, Miao F, Prakash NS, Venkatramani V, Gauri A, Alonzo D, Alameddine M, Swain S, Punnen S, et al. Comparison of readmission and short-term mortality rates between different types of urinary diversion in patients undergoing radical cystectomy. World J Urol. 2018;36:393-9.

6. Deliveliotis C, Papatsoris A, Chrisofos M, Dellis A, Liakouras C, Skolarikos A. Urinary diversion in high-risk elderly patients: modified cutaneous ureterostomy or ileal conduit? Urology. 2005;66:299-304.

7. Seo M, Langabeer li JR. Demographic and survivorship disparities in nonmuscle-invasive bladder Cancer in the United States. J Prev Med Public Health. 2018:51:242-7.

8. Mayr R, May M, Martini T, Lodde M, Comploj E, Pycha A, Strobel J, Denzinger S, Otto W, Wieland W, et al. Comorbidity and performance indices as predictors of cancer-independent mortality but not of cancerspecific mortality after radical cystectomy for urothelial carcinoma of the bladder. Eur Urol. 2012;62:662-70.

9. Miller DC, Taub DA, Dunn RL, Montie JE, Wei JT. The impact of co-morbid disease on cancer control and survival following radical cystectomy. J Urol. 2003:169:105-9.

10. Longo N, Imbimbo C, Fusco F, Ficarra V, Mangiapia F, Di Lorenzo G, Creta $\mathrm{M}$, Imperatore V, Mirone V. Complications and quality of life in elderly patients with several comorbidities undergoing cutaneous ureterostomy 
with single stoma or ileal conduit after radical cystectomy. BJU Int. 2016; 118:521-6.

11. De Nunzio C, Cindolo L, Leonardo C, Antonelli A, Ceruti C, Franco G, Falsaperla M, Gallucci M, Alvarez-Maestro M, Minervini A, et al. Analysis of radical cystectomy and urinary diversion complications with the Clavien classification system in an Italian real life cohort. Eur J Surg Oncol. 2013;39: 792-8.

12. Leow JJ, Cole AP, Seisen T, Bellmunt J, Mossanen M, Menon M, Preston MA, Choueiri TK, Kibel AS, Chung BI, et al. Variations in the costs of radical cystectomy for bladder Cancer in the USA. Eur Urol. 2018;73:374-82.

13. Berger I, Wehrberger C, Ponholzer A, Wolfgang M, Martini T, Breinl E, Dunzinger M, Hofbauer J, Holtl W, Jeschke K, et al. Impact of the use of bowel for urinary diversion on perioperative complications and 90-day mortality in patients aged 75 years or older. Urol Int. 2015;94:394-400.

14. Surveillance $E$, And end results (SEER) program (www.seer.cancer.gov) SEER*stat database: Incidence - SEER 18 Regs research data + hurricane Katrina impacted Louisiana cases, Nov 2018 sub (1975-2016 varying) - linked to county attributes - Total U.S., 1969-2017 counties. April 2019 edition: National Cancer Institute, DCCPS, Surveillance Research Program.

15. Freedman LS. Tables of the number of patients required in clinical trials using the logrank test. Stat Med. 1982;1:121-9.

16. Korkes F, Palou J. High mortality rates after radical cystectomy: we must have acceptable protocols and consider the rationale of cutaneous ureterostomy for high-risk patients. Int Braz J Urol. 2019;45:1090-3.

17. Martini A, Sfakianos JP, Renstrom-Koskela L, Mortezavi A, Falagario UG, Egevad L, Hosseini A, Mehrazin R, Galsky MD, Steineck G, Wiklund NP. The natural history of untreated muscle-invasive bladder cancer. BJU Int. 2020; 125:270-5.

18. Burkhard FC, Wuethrich PY. Cutaneous ureterostomy: 'back to the future'. BJU Int. 2016;118:493-4.

19. Suzuki K, Hinata N, Inoue TA, Nakamura I, Nakano Y, Fujisawa M. Comparison of the perioperative and postoperative outcomes of lleal conduit and cutaneous Ureterostomy: a propensity score-matched analysis. Urol Int. 2019:1-7.

20. Suzuki K, Hinata N, Inoue TA, Nakamura I, Nakano Y, Fujisawa M. Comparison of the perioperative and postoperative outcomes of ileal conduit and cutaneous ureterostomy: a propensity score-matched analysis. Urol Int. 2020;104:48-54.

21. Zattoni F, Palumbo V, Giannarini G, Crestani A, Kungulli A, Novara G, Zattoni F, Ficarra V. Perioperative outcomes and early survival in octogenarians who underwent radical cystectomy for bladder Cancer. Urol Int. 2018;100:13-7.

22. Garde H, Ciappara M, Galante I, Fuentes Ferrer M, Gomez A, Blazquez J, Moreno J. Radical cystectomy in octogenarian patients: a difficult decision to take. Urol Int. 2015;94:390-3.

23. Nogueira L, Reis RB, Machado RD, Tobias-Machado M, Carvalhal G, Freitas C Jr, Magnabosco W, Menezes CL, Corradi C, Reis LO, et al. Cutaneous ureterostomy with definitive ureteral stent as urinary diversion option in unfit patients after radical cystectomy. Acta Cir Bras. 2013;28(Suppl 1):43-7.

24. Williams SB, Kamat AM, Chamie K, Froehner M, Wirth MP, Wiklund PN, Black PC, Steinberg GD, Boorjian SA, Daneshmand S, et al. Systematic review of comorbidity and competing-risks assessments for bladder Cancer patients. Eur Urol Oncol. 2018;1:91-100.

25. Charlson ME, Pompei P, Ales KL, Mackenzie CR. A new method of classifying prognostic comorbidity in longitudinal studies: development and validation. J Chronic Dis. 1987:40:373-83.

26. McFerrin C, Raza SJ, May A, Davaro F, Siddiqui S, Hamilton Z. Charlson comorbidity score is associated with readmission to the index operative hospital after radical cystectomy and correlates with 90-day mortality risk. Int Urol Nephrol. 2019;51:1755-62.

27. Zabell JR, Adejoro O, Konety BR, Weight CJ. Risk of end stage kidney disease after radical cystectomy according to urinary diversion type. J Urol. 2015; 193:1283-7.

28. Gupta NP, Kolla SB, Seth A, Hemal AK, Dogra PN, Kumar R. Oncological and functional outcome of radical cystectomy in patients with bladder cancer and obstructive uropathy. J Urol. 2007;178:1206-11 discussion 1211.

\section{Publisher's Note}

Springer Nature remains neutral with regard to jurisdictional claims in published maps and institutional affiliations.

\section{Ready to submit your research? Choose BMC and benefit from:}

- fast, convenient online submission

- thorough peer review by experienced researchers in your field

- rapid publication on acceptance

- support for research data, including large and complex data types

- gold Open Access which fosters wider collaboration and increased citations

- maximum visibility for your research: over $100 \mathrm{M}$ website views per year

At BMC, research is always in progress.

Learn more biomedcentral.com/submissions 